introduction to a possibility in pathogenesis, but it will be necessary to confirm the theory unfolded by demonstrating some real noxus between the human corpus luteum and true human eclampsia. For example, appeal might justifiably be made to microscopical examination of the corpus luteum in toxæmia to show some departures in structure, size, or degree of degeneration from the corpus luteum of normal pregnant women at term. During the preceding yeas Dr. W. Newcomb has examined at St. Mary's Hospital six corpora lutea removed by me during Crsarean section at term, two from cases of eclampsia, two from other forms of toxic albuminuria, and two from nontoxic women, but he assures me that so far it has not been possible to detect any points by which the corpora lutea of toxic patients could be distinguished from those of normal women. The mere size of the body is notoriously variable whether the patient be toxic or not, but it is conceivably possible, however, that either the production of the toxin is associated with changes so subtle as not to be visible microscopically, or else that the clinical symptoms are the result of failure to neutralise a toxin thrown off by the corpus luteum in every normal pregnancy. Further, if this theory be correct removal of the corpus luteum during Cæsarean section for eclampsia should have a marked and immediate effect on the course of the symptoms, for one of the commonest criticisms of the placental theory is the frequent persistence of fits after the placenta has been expelled. In the four cases in which I removed the corpus luteum one had two fits during the ensuing 12 hours, another of albuminuria with sudden exacerbation of symptoms remained in a severely toxic state with oedema and mental aberration for three days, in a third toxic vomiting of late pregnancy ceased immediately, while of the fourth I have not the notes available. The number of cases is small, but their after-history did not differ from that ordinarily observed. Many further observations on the effect of the removal of the corpus luteum are necessary before any reliable conclusions can be arrived at, and, as this procedure scarcely adds one minute to the time of the operation, the suggestion is thrown out that this should be done as opportunity offers in clinical practice.

Not the least interesting part of the authors' paper is that which deals with the effect of cholesterol in neutralising the action of the toxins. Cholesterol was suggested by Decio (Annali di Ostetricia) in 1913 as being the natural defence of the pregnant woman against ever-present poisons circulating in her blood. Should the experimental ouservation on this point be substantiated by their extended work, this also suggests still further therapeutic possibilities. Those of us who are interested in this problem will look forward to a subsequent communication by Dr. Wallis and Dr. Williams, giving their experience of a further series of experiments.

$$
\text { I am, Sir, yours faithfully, }
$$

$$
\text { Aleck W. Bourne. }
$$

Harley-street, W., A pril 30th, $192 \bar{z}$.

\section{PERNICIOUS VOMITING OF PREGNANCY.}

To the Editor of THE LANCET.

SiR,-In your issue of April 15th Mr. John S. Fairbairn suggests, in order to explain and reconcile the two different views which are held of the nature of the pernicious vomiting of pregnancy, that the condition should be classified into two varieties, one occurring in the earlier months, which is always of neurotic origin, and the other in the last two months, which is toxæmic in nature. Such a distinction cannot be applied to my cases, because four out of 29 occurred within the last two months of pregnancy and differed in no way as to their symptoms and their response to institutional treatment from the cases in which the pregnancy was of two to four months' duration. Moreover, the vomiting which occurs in the toxic conditions which Mr. Fairbairn mentions is only an incident in those diseases, just as it is in cases of appendicitis, rotation of pedicle of an ovarian cyst, degenerating fibroid or pyelitis occurring in pregnancy But the pernicious vomiting of pregnancy is a very different condition. In the duration, persistence; and frequency of the vomiting it is unlike any other form of vomiting. It is a definite, well-recognised, and unmistakable disease, and it would be unscientific and confusing to classify the occasional and infrequent vomiting which occurs in the albuminurias of pregnancy as a variety of such a distinct condition as the pernicious vomiting of pregnancy.

It is clear to my mind that the two views of the nature of this remarkable condition are irreconcilable, for they are directly opposed to one another. According to the toxæmic theory the toxæmia, the existence of which is unquestioned, is the cause of the persistent vomiting, whereas it is the effect of the vomiting according to the neurosis theory. I think it may be safely asserted that most obstetricians at the present time are of the opinion that as a rule cases of pernicious vomiting of pregnancy are of neurotic origin, but they are not prepared to go so far as to say that all cases are of this nature. They would admit that the severest forms of the disease, with jaundice, loss of weight tachycardia, pyrexia, \&c., may be due to a neurosis only, and that during life the two varieties may be indistinguishable, but if the patient dies, they would regard the case as of toxæmic origin. Surely such a distinction is unreasonable and futile.

In your excellent leading article (April 22nd) it is stated that the fact that glucose injections were used in my cases lessens the value of the conclusions I have drawn from my experience of the treatment of this disease. I think you will agree that the objection does not hold good, when I state that glucose was not used in all my cases, that it was used in some of them before they were admitted for institutional treatment and did not check the vomiting, and in many cases that did receive glucose the patient had taken food and kept it before a glucose enema was given. Important as the question of the nature of this condition is, the question of treatment is greater. I think all obstetricians of experience will agree with the concluding remarks of your leading article, that in future the operation of induction of abortion will be very rarely performed by obstetricians for the pernicious vomiting of pregnancy.

I would add, although this is not relevant to the subject, that there are few, if any, conditions in which induction of abortion is advisable.

I am, Sir, yours faithfully,

Leeds, May 1st, 1922. C. OLdFIELd

\section{THE HYSTERICAL NATURE OF SO CALLED} "PERNICIOUS" VOMITING IN PREGNANCY.

\section{To the Editor of THE LANCET.}

SIR,-In Mr. T. W. Eden's letter published in your issue of April 29th he complains that I did not quote from the latest edition of his book. I have, however, only followed the example he set in his first letter, published a fortnight ago, in which he quoted from the third of his five editions. As a matter of fact, on comparing the fourth edition of 1915 , from which I quoted, with the fifth and latest edition of 1919 I find that Mr. Eden's complaint is quite unjustified, as the section on vomiting of pregnancy is identical in the two, with the single exception of a sentence which reads " the urine, although diminished in quantity, from vomiting or from diminished intake of fluid, remains otherwise healthy." In the fifth edition the words " free from all blood and casts " are substituted for " otherwise healthy." This alteration does not bear in the least upon our discussion, as neither blood nor casts were mentioned by either of us, and $\mathrm{Mr}$. Eden's original criticism was in connexion with the ammonia coefficient of the urine, the references to which are identical in the two editions.

$$
\text { I am, Sir, yours faithfully, }
$$
ARTHUR F. HuRst

New Lodge Clinic, Windsor Forest, May 1st, 1922. 